\title{
A simplified global vegetation model for deep time.
}

KHUSHBOO GURUNG ${ }^{1}$, BENJAMIN J. W. MILLS ${ }^{2}$ SARAH BATTERMAN ${ }^{1,3}$, YVES GODDÉRIS ${ }^{4}$, YANNICK DONNADIEU $^{5}$, PHILIPP PORADA ${ }^{6}$ AND KATIE FIELD $^{7}$

${ }^{1}$ University of Leeds

${ }^{2}$ School of Earth and Environment, University of Leeds

${ }^{3}$ Cary Institute of Ecosystem Studies

${ }^{4}$ Géosciences Environnement Toulouse

${ }^{5}$ CEREGE, Aix Marseille University

${ }^{6}$ University of Hamburg

${ }^{7}$ University of Sheffield

Presenting Author: bskgu@leeds.ac.uk

Plant emergence and evolution were key events in the Phanerozoic Eon that helped shape the landscape and climate of the Earth. Land plants are a major contributor to global biomass and primary productivity, which influences atmospheric carbon dioxide and oxygen levels as well as biogeochemical cycles of oxygen and nutrients. Long-term climate change is therefore controlled, to some degree, by the interaction between plants and atmospheric carbon. However, the representation of the terrestrial biosphere in long term biogeochemical models is currently very poor.

Here we develop a simplified Dynamic Global Vegetation Model (DGVM) which can provide first-order constraints on vegetation biomass and its effect on global biogeochemistry in deep time. Temperature, $\mathrm{CO}_{2}$ levels, photosynthetically-active radiation and water availability are environmental factors which limit plant biomass in our model, and we show that the model is capable of capturing present day biomass patterns when subject to this information for the present day.

In deep time, changes in these environmental parameters lead to fluctuations in predicted biomass. For example, we predict that the breakup of the supercontinent Pangaea ( 200 million years ago) was a time of beneficial environmental changes for plants which result from changes in the hydrological cycle. Further development of this model includes better representation of plant functional types (i.e. gymnosperm and angiosperm), and integration into climate-biogeochemical models. Such models can help us decipher events that may have led to the diversification and success of plants on land and to evaluate the extent that these changes influence the carbon cycle and in turn climate. 